\title{
Room for hope after a chemical defeat
}

The Clinton administration blinked and a small group of arch-conservatives dealt an unexpected blow to the Chemical Weapons Convention. The treaty has its weaknesses, but it merits greater faith in its strengths.

IF ever there was an object lesson in the perils of complacency, last week's Republican snatching of defeat from the jaws of a Clinton victory has provided it. A decision to postpone ratification by the US Senate of the Chemical Weapons Convention (CWC) could have been avoided had the arch-conservative Jesse Helms not succeeded in delaying its consideration last year; if hard-line Republican activists had thus been prevented from developing an anti-treaty lobby amongst small chemical companies; and if Republicans in the Senate had not then been able surreptitiously to use it to persuade their colleagues, and their leader, Robert Dole, that here was a handy way to differentiate themselves from the Democrats during the run-up to an election.

That, rather than deep reconsiderations of the rights and wrongs of the convention, is what allowed Republican senators to carry the day last week. No-one is defending possible military deployment or trade in nerve agents such as sarin, soman and tabun, mustard agents, hydrogen cyanide, and biochemical toxins. No opposition has been voiced to the requirement of the convention that an international agency be set up in the Hague to implement the treaty's provisions; that signatories should declare their chemical weapons stocks and plans to destroy them within ten years of the treaty coming into force, and to close production facilities; or that signatories should be open to inspection.

The electoral tactics were successful because opponents have been able to attack the treaty's soft underbelly. Companies, they say, could find themselves forced to be open to inspection at the whim of other signatory countries. To make matters worse, the inspectors might come, for example, from two of the nations least trusted by US industrialists: Japan and France (both with past episodes of industrial espionage). Then there would be all that bureaucratic form-filling insisted on by the Hague agency. And, they say, one should consider ratifying the convention only if Iraq, Iran and Libya will sign up to it.

To give these countries such a veto would be a sure way of scuppering the convention. That posture should be dismissed as the spoiling tactic that it is. But the other concerns are less easily dealt with, because there is an element of truth in them. "Suck it and see" is the flavour of the response of treaty supporters to them. In its favour, the convention is stiff with provisions ensuring that those protesting against an inspection, or aspects of it, get their hearing, and that a substantial majority of signatories then have to be convinced that the inspection is indeed called for. Strength is added to the treaty defenders' case by the fact that 63 countries have already signed up to it, including some that are hardly negligible in their chemical interests such as Germany, the United Kingdom and Sweden. Sixtyfive are required for the convention to come into force.

Another problem for treaty proponents is that the role of chemicals is not always unambiguous. If a developing country is found to be harbouring large stocks of $O$-ethyl dimethylamidophosphorylcyanide, one can be certain that it is willing to destroy the nervous systems of its opponents. In contrast, a cache of isopropanol may be, but is not necessarily, intended to be mixed with other compounds in a binary weapon to rain sarin on the heads of enemies. All the same, a major munitions effort does tend to leave its traces, and one can set considerable store by a combination of satellite surveillance, intelligence and the on-site inspections specified in the convention.

Such considerations may all be beside the point in the United States if last week's events are a political anomaly - an obstacle riding a wave of temporary political cohesiveness that will evaporate in the convention's favour if President Bill Clinton is reelected. Domestic considerations in the CWC's favour are strong: the influence of the United States on the treaty's implementation will be minimized if it stays out while 65 others ratify it. (But a de facto presence would still be felt, given the country's sheer chemical prowess and its extensive past involvement in the convention's development.)

One factor that will help to tip the scales, apart from the weakness of the opponents' case, is the fact that major chemical companies stand to lose substantial exports, following embargoes that can be applied to non-signatories under the terms of the convention five years after it comes into force. But nevertheless, if re-elected, Clinton and his administration will need to concentrate much harder the next time the CWC surfaces in the Senate.

\section{BSE's propaganda}

The UK government's public deployment of a Nature paper encourages incorrect perceptions of the role of science.

Clutching a copy of R. M. Anderson et al. (Nature 382, $779-788 ; 1996)$ the British government this week asked the European Commission to reduce a cull of 127,000 cattle demanded by the commission as part of plans to reduce the incidence of bovine spongiform encephalopathy (BSE) in the UK herd. The paper's epidemiological analysis of the BSE epidemic suggests that this will cease around 2001 even without culling, and that no culling strategy short of shooting almost 3 million cattle would make a significant dent in the epidemic before then (see page 209). According to the government (in public, at least), this justifies doing nothing.

Britain's European neighbours are not so sanguine. The UK government's credibility in the eyes of the continental European public could hardly be lower. And what surprises Britain's neighbours most is why Britain is making such a fuss about the cull. And they argue that, according to the same analysis, a cull of 150,000 cows could eliminate more than 2,000 (or about a third) of the total cases predicted to occur before the end of the epidemic. Britain has culled similar numbers during other epidemics. To other Europeans, arguing about the rationality of the public's response or the scientific grounds for the cull seems neither here nor there.

The role of science, with its attendant uncertainties, is to illuminate political choices, not to enforce them. By acting as if it is oblivious to this truth, and to European political reality, the UK government can only erode its credibility even further. 